\title{
Effect of solar radiation on cooking/drying process of grapes using solar oven.
}

\author{
Bailey, J. ${ }^{\text {; }}$ Castro-Giráldez, M. ; Esteves, A.b; Fito, P. J. ${ }^{*}$

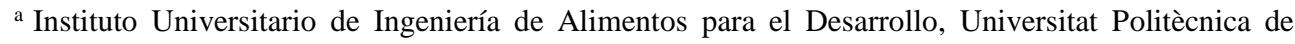 \\ València, Camino de Vera s/n, 46022 Valencia, Spain.

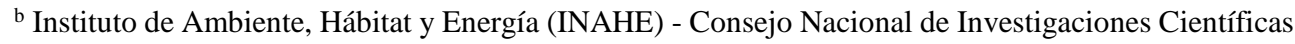 \\ y Técnicas (CONICET) - CCT-Mendoza, Av. Ruiz Leal s/n - Parque Gral. San Martín (5500), \\ Mendoza, Argentina
}

*E-mail of the corresponding author: pedfisu@tal.upv.es

\begin{abstract}
Solar ovens have become a very popular technology for cooking, specially, in underdeveloped countries where access to firewood is scarce, time consuming and expensive. The benefits of solar cooking are multiple, such as saving money, as this device requires no fuel, as well as having an important impact in the environment, decreasing carbon dioxide emissions and decreasing deforestation.

One challenge for food industry is to get to know the behaviour of food cooked with solar technology. The aim of this study was to model the drying process of white and red grape in solar oven using thermodynamics and spectrophotometry measurements, controlling the irradiation effect blocking the Ultraviolet radiation using a polarized vinyl film
\end{abstract}

Keywords: sun radiation; thermodynamics; solar oven; drying. 


\section{Introduction}

Grape is the second most widely cultivated fruit in the world after the orange and it is of great commercial interest [1]. It contains large amounts of phytochemicals including phenolics, flavonoids, anthocyanins and resveratrol, which offer health benefits. Antioxidant compounds include vitamins, phenols, carotenoids, and flavonoids. Among the last group, flavones, isoflavones, flavanones, flavonols, anthocyanins and catechins are the most important, and exhibit substantial antioxidant activity [2]. The high content of grapes in phenolics, flavonoids, and anthocyanins have been suggested to be responsible for their health benefits [3] and these benefits have been well described [4].

Other benefits, as described by Meng et al (2017) ${ }^{[5]}$ such as Melatonin, which was recently reported to be present in wine in 2008, as well as resveratrol and hydroxytyrosol, are regarded as bioactive compounds in grapes and wines and have positive effects for human health.

Regarding the drying of this fruit, it is a slow and energy intensive process because the waxy peel has low permeability to moisture [6]. Nevertheless, Peinado et al. (2013) ${ }^{[7]}$ reported that Pedro Ximenez grapes, exposed to sunlight, presented a higher antioxidant capacity than fresh grapes. Thus it is reasonable to infer that both UV radiation and temperature bring about changes in the phenolic profile when fresh grapes are processed into raisins by sun drying.

Drying is one of the most commonly followed methods of preservation for fruits, vegetables and fruit products [8]. Natural sun drying of fruits is still practiced largely unchanged from ancient times in many tropical and subtropical countries. This method is the cheapest and is successfully employed in grapes producing countries. In many of these countries, more than $80 \%$ of food is being produced by small farmers in developing countries. These farmers dry food products by natural sun drying, an advantage being that solar energy is available free of cost, but there are several disadvantages which are responsible for degradation and poor quality of the end product [9].

In many rural locations in Africa and most developing countries, grid-connected electricity and supplies of other non-renewable sources of energy are either unavailable, unreliable or, for many farmers, too expensive. Thus, in such areas, crop drying systems that employ motorised fans and/or electrical heating are inappropriate. The large initial and running costs of fossil fuel powered dryers present such barriers that they are rarely adopted by small scale farmers. The traditional open sun drying utilised widely by rural farmers has inherent limitations: high crop losses ensue from inadequate drying, fungal attacks, insects, birds and rodents encroachment, unexpected down pour of rain and other weathering effects. In such conditions, solar-energy crop dryers appear increasingly to be attractive as commercial propositions [10]. 
In pursuit of achieving the Sustainable Development Goals (SDGs) - and previously the Millennium Development Goals - introducing clean cooking technologies remains a popular option for development actors. One such technology is the solar cooker (SC), a device that makes direct use of sunlight to cook food or pasteurize drinks. While there are multiple designs, the general principle is that these devices channel and concentrate sunlight through mirrors, which is then converted to heat and used for cooking [11].

Thermodynamically, multiple studies were carried out by this research group regarding structural changes of meat as consequence of drying process. The infrared thermography (IRT) has shown to be a valuable tool to carry out studies regarding the infrared spectrum, as it is a non-contact and non-destructive method that provides temperature information of the whole body and not only one point [12, 13, 14].

The aim of this study was to model the drying process of white and red grape in solar oven using thermodynamics and spectrophotometry measurements, controlling the irradiation effect by blocking the Ultraviolet radiation using a polarized vinyl film.

\section{Materials and Methods}

\subsection{Materials}

Experiments were carried out using two different types of grapes (Vitis vinífera): red table grape "Red Globe” and white table grape "Regal”. Both types of grapes were bought at local commerce in Valencia, Spain, and selected according to their homogeneity in size and color. They were stored at $8^{\circ} \mathrm{C}$ until usage in sample cups, sealed with Parafilm ${ }^{\circledR}$ in order to avoid water losses.

\subsection{Physicochemical Determinations}

Mass was determined by using a Mettler Toledo Balance $( \pm 0.0001)$ (Mettler-Toledo, Inc., USA).

The water activity $\left(\mathrm{a}_{\mathrm{w}}\right)$ was determined by a dew point Hygrometer Decagon (Aqualab ${ }^{\circledR}$, series 3 TE, Decagon Devices, Pullman, WA, USA), with precision $\pm 0,003$. Moisture was determined by drying in a vacuum oven at $60^{\circ} \mathrm{C}$ until constant weight was reached (AOAC Method 934.06, 2000). Soluble solids content of the pulp liquid phase was determined by the refractometetric index ( ${ }^{\circ} \mathrm{Brix}$ ) with a refractometer calibrated with distilled water at $25{ }^{\circ} \mathrm{C}$ (ABBE, ATAGO Model 3-T, Japan).

\subsection{Drying process}

A solar oven (model Suntaste Compact, SunOK, Portugal) of 52x43x32 cm was used for the drying. Samples were placed in the described order in the middle of the oven, close to the door, in order to favor its drying. The door of the oven was not fully closed, leaving a $10 \mathrm{~cm}$ space at the upper surface to enable drying and images from an infrared camera Optris $\mathrm{PI}^{\circledR}$ 
160 thermal imager (Optris GmbH, Berlin, Germany). This setup was located approximately at $20 \mathrm{~cm}$ of the sample surface and at an angle of $45^{\circ}$ relative to the plane in which the samples were placed. The camera was connected to a computer to record. A certified emissivity label of $25 \mathrm{~mm}$ diameter $(\varepsilon=0.95)$ (Optris $\mathrm{GmbH}$, berlin, Germany) was used as a reference emitter to calculate the reflected energy received by the infrared camera.

Temperatures during drying were controlled by 5 K-thermocouples and 2 radiofrequency sensors connected to an Agilent multiplexer 34972A data acquisition system (Agilent Technologies, Malaysia) and registered by Agilent.

At the same time as the drying started and the registering of temperatures, radiofrequency and infrared images were recorded, manual analysis were carried out every fifteen minutes: the air velocity was measured inside the oven and outside with a digital anemometer (Proster ${ }^{\circledR}$ RoHS, Model PST-TL090 series, wind accuracy $\pm 5 \%$ China). Air humidity was also registered in and out with a humidity meter (TRACKlife, RoHS, Model HM01, accuracy $\pm 3 \% \mathrm{RH}$ at $25{ }^{\circ} \mathrm{C}, 20 \%-80 \% \mathrm{RH}, \pm 3.5 \% \mathrm{RH}$ at other ranges, China) and thirdly, day light intensity and in the solar oven was registered with a digital luxometer (D-LUXmeter, RoHS, accuracy $\pm 4 \%$, resolution $0.1 \mathrm{~lx}$, range 0,1-200,000 lx, resolution 0,1 lx, China).

Procedure difference was that on one of the days, a window vinyl film with control heat and 96\% UV rays blockage was placed over the solar oven's glass (Rabbitgoo ${ }^{\circledR}, A 023-45 B$, China) and on the other day the oven's glass had no vinyl. The vinyl is PVC electrostatic film plus a back with PET release film.

\subsection{Solar Oven}

The solar oven (SunTaste, SunOk®C, Portugal) is made out of cork agglomerate with water based varnish to diminish UV effects. It also contains aluminium and an ultra-clear glass cover of $4 \mathrm{~mm}$ thickness with a UV transmittance $\left(\mathrm{T}_{\mathrm{uv}}\right)$ of $84.5 \%$.

A solar box cooker basically consists of an insulated box with a transparent glass cover and reflective surfaces to direct sunlight into the box. The inner part of the box is painted black in order to maximize the sunlight absorption.

\subsection{Infrared measurements}

Thermal images were acquired using the Optris $\mathrm{PI}^{\circledR} 160$ thermal imager (Optris GmbH, Berlin, Germany). It uses a two-dimensional Focal Plane array with 160 x 120 pixels, a spectral range of 7.5-13 $\mu \mathrm{m}$, resolution of $0.05^{\circ} \mathrm{C}$ and an accuracy of $\pm 2 \%$. The camera covers a temperature range of -20 to $100{ }^{\circ} \mathrm{C}$. It has a field view of $23^{\circ} \mathrm{x} 17^{\circ}$ with a minimal focus distance of $0.02 \mathrm{~m}$. The camera is supported by the software Optris PI Connect (Optris GmbH, Berlin, Germany).

$21^{\text {ST }}$ INTERNATIONAL DRYING SYMPOSIUM EDITORIAL UnIVERsitat POLITÈCNICA DE VALÈNCIA 


\section{Results and discussion}

The heating process of the red and white grape surface was produced by a combined effect of absorption of photon energy in the solar spectrum and by convection heat transmission with the air inside the solar oven. Figure 1 shows a sequence of treatment monitored by IRT, where it is possible to observe how the samples are heated by IRT (thermal infrared).

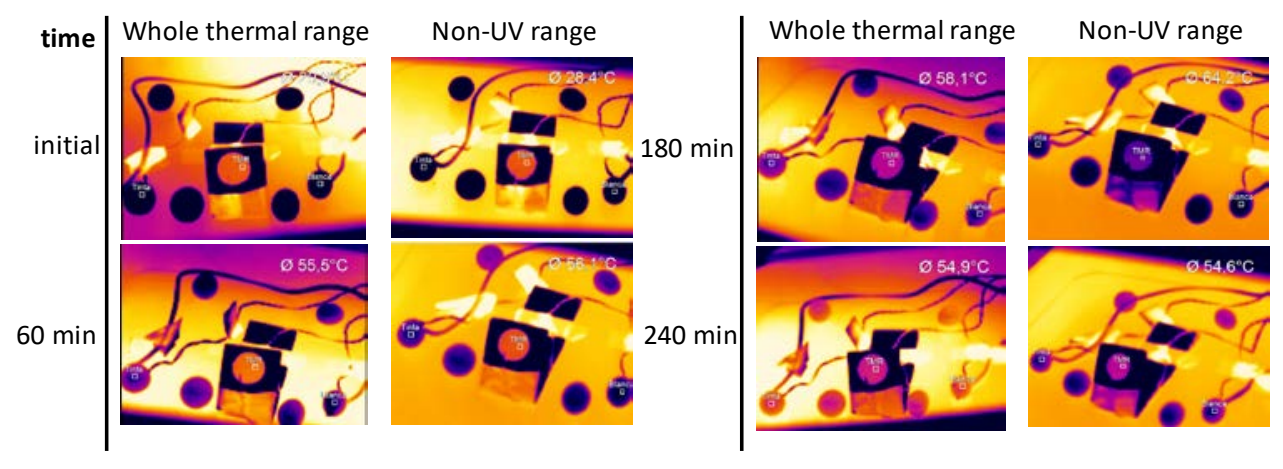

Figure 1. Sequence of grapes heating analized by IRT, for treatment with whole thermal infrared and for same range without the ultraviolet range.

Figure 2a and $\mathrm{b}$ show the surface temperature of the samples and of the air temperature with respect to the treatment time, where it is possible to observe how the temperature of the samples is always above that of the air. This behaviour occurs in both treatments, with ultraviolet spectrum and without this section of the spectrum. However, analyzing the internal and external measurements of light intensity in figure 2c and d, it is possible to observe how the effect of the solar oven mirrors cause an increase of the internal intensity in the treatment that include the ultraviolet range but this does not occur in the other treatment, when the ultraviolet spectrum is blocked.

Applying an energy balance on the surface of the samples, it is possible to calculate the amount of thermal energy accumulated as the addition of the heats received by radiation and by convection, see equation 1 .

$$
\frac{\mathrm{dE}}{d t}=q_{\text {rad }}+q_{\text {conv }}
$$

Only the internal energy will accumulate because most of the sun spectrum that receives the surface is the thermal spectrum (IR, VIS and UV), with small radiation at lower frequencies (RF and MW) and nil at higher frequencies. Therefore, it is possible to estimate the temperature increasement by time measured by TIR, mass of sample and specific heat estimated by Chen model.

$$
\frac{\mathrm{dE}}{d t}=\frac{\mathrm{dU}}{d t}=M C_{P} \frac{d T}{d t}
$$


For a natural convection (measuring the air velocity and relative humidity) it is possible to calculate the individual heat coefficient, and with the temperature difference between the surface and the air it is possible to estimate the heat loss to the environment.

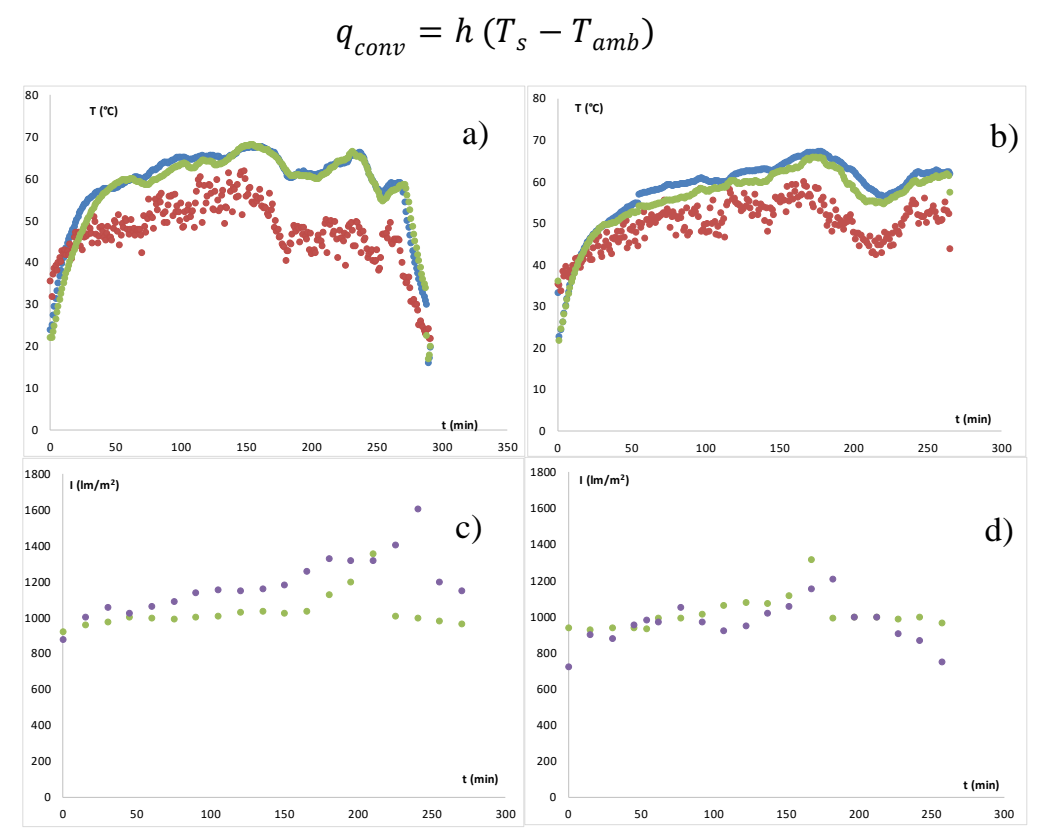

Figure 2. a) and b) represents the air temperature (๑), red grape surface temperature $(\bullet)$ and white grape surface temperature ( () , and c) and d) the light intensity express in $1 \mathrm{~m} / \mathrm{m} 2$ for external $(\bullet)$ to the solar oven and internal (•). Where a) and c) represents treatment with whole thermal range radiation and $b$ ) and d) for same range radiation without the ultraviolet spectra.

Figure 3 shows the accumulation energy in the samples, the heat losses to the air and the heat gain by radiation, where it is possible to observe how the infrared and visible range are the most important for the warming because differences are not appreciated between both treatments. 
Finally, the results of the drying process are shown in table 1, where it is possible to observe how dehydration occurs in the high moisture isotherm section, where small variations of water activity (in this case not significant) represent high variations in moisture (in this case very significant) producing a $20 \%$ of weight loss in all samples. However, there are no differences between treatments with or without ultraviolet spectrum.

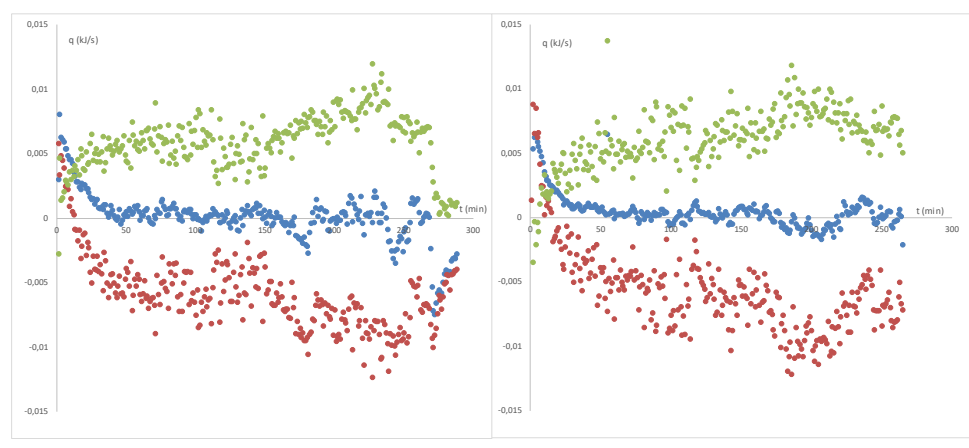

Figure 3. represents the energies (kJ/s) explained on equation 1 applied in white grape; where (•), represents the convection heat (eq. 3); (•) represents the accumulated internal energy (eq. 2) and $(\bullet)$ represents the radiation heat. a) represents treatment with whole thermal range radiation and b) for same range radiation without the ultraviolet spectra.

Table 1. Initial and final physical and compositional values of samples in both treatments.

\begin{tabular}{|c|c|c|c|c|c|c|c|c|}
\hline & \multicolumn{3}{|c|}{ initial } & \multicolumn{4}{|c|}{ final } \\
\hline & & $x w\left(k_{w} / k_{T}\right)$ & zs (으ix) & $a_{w}$ & $\mathrm{xw}\left(\mathrm{kg}_{\mathrm{w}} / \mathrm{kg}_{\mathrm{T}}\right)$ & zs (ㅇix) & $a_{w}$ & $\Delta \mathrm{M}(\mathrm{kg} / \mathrm{kg})$ \\
\hline \multirow{2}{*}{ thermal range } & Red grape & $0,870 \pm 0,002$ & $9,70 \pm 0,14$ & $0,984 \pm 0,002$ & $0,83 \pm 0,05$ & $11,7 \pm 1,1$ & $0,980 \pm 0,005$ & $-0,20 \pm 0,08$ \\
\hline & White grape & $0,807 \pm 0,002$ & $16,80 \pm 0,15$ & $0,977 \pm 0,003$ & $0,76 \pm 0,02$ & $21 \pm 2$ & $0,971 \pm 0,004$ & $-0,20 \pm 0,08$ \\
\hline \multirow{2}{*}{ non-UV range } & Red grape & $0,870 \pm 0,002$ & $9,70 \pm 0,14$ & $0,984 \pm 0,002$ & $0,85 \pm 0,02$ & $11,9 \pm 0,7$ & $0,9849 \pm 0,0010$ & $-0,21 \pm 0,05$ \\
\hline & White grape & $0,807 \pm 0,002$ & $16,8 \pm 0,15$ & $0,977 \pm 0,003$ & $0,785 \pm 0,009$ & $20,4 \pm 0,8$ & $0,9741 \pm 0,0006$ & $-0,20 \pm 0,03$ \\
\hline
\end{tabular}

\section{Conclusions}

It has been shown that it is possible to remove the irradiating solar spectrum or ultraviolet range, which generates food oxidation, with no decrease of the heating capacity or dehydration of a solar oven.

\section{Acknowledgements}

The authors Pedro J. Fito and Marta Castro-Giraldez acknowledge the financial support from the Spanish Ministerio de Economía, Industria y Competitividad, Programa Estatal de I+D+i orientada a los Retos de la Sociedad AGL2016-80643-R, Agencia Estatal de Investigación (AEI) and Fondo Europeo de Desarrollo Regional (FEDER). The autor Jannika Bailey wants to thank "Servicio Español para la Internacionalización de la Educación (SEPIE)”, Bec.ar and "Consejo Nacional de Investigaciones Científicas y Técnicas (CONICET)" for the support in her PhD studies, as well as her mobility and stay in Spain. 


\section{References}

[1] Azzouz, S.; Hermassi, I.; Toujani, M.; Belghith, A. (2016). Effect of drying temperature on the rheological characteristics of dried seedless grapes. Food and Bioproducts Processing, 100 (A), 246-254.

[2] Wang, H.; Cao, G.; Prior, R.L. (1997). Oxygen radical absorbing capacity of anthocyanins. J.Agric. Food Chemistry, 45, 304-309.

[3] Yang, J.; Martinson, T.E.; Liu, R.H. (2009). Phytochemical profiles and antioxidant activities of wine grapes. Food Chemistry, 116 (1), 332-339.

[4] Fabani, M.P.; Baroni, M.V.; Luna, L.; Lingua, M.S.; Monferran, M.V.; Paños, H.; Tapia, A.; Wunderlin, D.A.; Egly Feresin, G. (2017). Changes in the phenolic profile of Argentinean fresh grapes during production of sun-dried raisins. Journal of Food Composition and Analysis, 58, 23-32.

[5] Meng, J.-F.; Shi, T.-C.; Song, S.; Zhang, Z.-W.; Fang, Y.-L. (2017). Melatonin in grapes and grape-related foodstuffs: A review. Food Chemistry, 231, 185-191.

[6] Adiletta, G.; Russo, P.; Senadeera, W.; Di Matteo, M. (2016). Drying characteristics and quality of grape under physical pretreatment. Journal of Food Engineering, 172, 9-18.

[7] Peinado, J.; López de Lerma, N.; Peralbo-Molina, A.; Priego-Capote, F.; de Castro, C.; McDonagh, B. (2013). Sunlight exposure increases the phenolic content in postharvested white grapes. An evaluation of their antioxidant activity in Saccharomyces cerevisiae. Journal of Functional Foods. 5 (4), 1566-1575.

[8] Prakash, O.; Kumar, A. (2017). Solar Drying Technology: Concept, design, testing, modeling, economics and environment. Green energy and technology, 1, 3-38.

[9] Jairaj, K.S.; Singh, S.P.; Srikant, K. (2009). A review of solar dryers developed for grape drying. Solar Energy, 83 (9), 1698-1712.

[10] Ekechukwu, O.V.; Norton, B. (1999). Review of solar-energy drying systems II: an overview of solar drying technology. Energy Conversion and Management, 40 (6), 615655.

[11] Iessa, L.; De Vries, Y.A.; Swinkels C.E.; Smits, M.; Butijn, C.A.A. (2017). What's cooking? Unverified assumptions, overlooking of local needs and pro-solution biases in the solar cooking literature. Energy Research \& Social Science, (28), 98-108.

[12] Traffano-Schiffo, M.V., Castro-Giraldez, M., Colom, R.J., Fito, P.F. (2015). Study of the application of dielectric spectroscopy to predict the water activity of meat during drying process. Journal of Food Engineering, 166, 285-290.

[13] Traffano-Schiffo, M.V., Castro-Giráldez, M., Fito, P.J., Balaguer, N. (2014). Thermodynamic model of meat drying by infrarred thermography. Journal of Food Engineering, 128, 103-110.

[14] Cuibus, L., Castro-Giráldez, M., Fito, P.J., Fabbri, A. (2014). Application of infrared thermography and dielectric spectroscopy for controlling freezing process of raw potato. Innovative Food Science \& Emerging Technologies, 24, 80-87. 